\title{
Curve fitting the hydrodynamic and dispersion characteristics of pollutant released in an inland water system
}

\author{
Baridakara Nwidadah ${ }^{1, *}$ and Olalekan Michael Adeloye ${ }^{2}$ \\ ${ }^{1}$ Master student, Department of Environmental Engineering and Technology, University of Port Harcourt. \\ ${ }^{2}$ Doctoral student, Department of Chemical/Petrochemical Engineering, Rivers State University, Port Harcourt.
}

Publication history: Received on 12 November 2020; revised on 20 November 2020; accepted on 21 November 2020

Article DOI: https://doi.org/10.30574/gjeta.2020.5.2.0098

\begin{abstract}
The research study was performed by estimating the longitudinal dispersion coefficient for Dor Nwezor section of BodoBonny River and conducting a tracer experiment using the constant distance variable time method. Eleven empirical models for the prediction of longitudinal dispersion coefficients were considered and analyzed using the hydraulic and geometric parameters of the river. The empirical and experimental results were analysed and compared statistically with Deng et al model yielded the most reliable method of predicting the longitudinal coefficient of dispersion of Dor Nwezor section of Bodo-Bonny River with the least root mean square value of 0.1221 , mean absolute value of 0.0617 close to zero and discrepancy ratio of -0.2303 that falls within the accepted accuracy range of -0.3 to 0.3 .
\end{abstract}

Keywords: Bodo-Bonny River; Dispersion Coefficient; Discrepancy Ratio; Mean Absolute Error; Root Mean Square.

\section{Introduction}

The chances that a pollutant, sewage, industrial waste, run offs, chemical wash offs into a water bodies (rivers, lakes, streams, ocean) is of a major disturbance to those diverting and consuming water from such sources. A method of rapidly estimating travel time or dispersion rate of pollutants is needed for pollution control or force warning system on streams where data are limited. As greater demands are placed on streams by communities, the evaluation of significant parameters of self-purification, such as de-oxygenation and re-aeration properties, becomes increasingly necessary. Therefore, the ability to simulate potential pollution buildup in streams, lakes, estuaries, and the likes becomes increasingly important[1] Thus, dispersion is associated with both longitudinal, and axial transportation of material due to its molecular dissemination, turbulent eddies, and velocity variance[2] Longitudinal dispersion is the action by which water flowing in a stream or river spreads out to dilute mass of pollutants, Rather than moving it downstream as a slug, such a mass is dispersed in the direction of flow of the river at different speeds [3]

Hydrodynamics is simply the study of a fluid in motion [4] Hydrodynamic properties of a fluid in motion include flow rate, velocity, temperature, pressure, density, all as a function of space and time [5] Hydrodynamics and pollutant emission dispersion characteristics of water bodies are important variables in the planning, management of river basin, and in hydraulic modeling with major consideration to aquatic ecosystems protection and different water usages [6].

\subsection{Study Area}

Ogoniland in South-South region is divided administratively into four Local Government Areas (Eleme, Gokana, Khana, and Tai), made up of six kingdoms (babbe, Eleme, Gokana, ken-khana, nyo-khana, and Tai) covering some $1,000 \mathrm{~km}^{2}$ in the south-east of the Niger Delta basin. It has a population of close to 832,000 according to the 2006 National Census with a $2.5 \%$ growth rate between $2007-2010$, it was recorded as 914,899 consisting mainly of the Ogoni people and

\footnotetext{
${ }^{*}$ Corresponding author: Baridakara Nwidadah

Master student, Department of Environmental Engineering and Technology, University of Port Harcourt. 
characterized by typically deltaic features such as uneven terrain, numerous creeks, shallow brackish water bodies and a variety of vegetation types including swamp forest [7].

Bodo City is a coastal community in the Ogoni area of rivers state, located in the Gokana Local Government Area, characterized by an annual rainfall of about 2000-3000 mm, which decreases sharply as one moves inland, with the rainy season from April to November and the short dry season which lasts for four months (from December to March) with occasional rainfall. Bodo Creek is a network of brackish water creeklets surrounding Bodo City on the upper axis of the Bonny-Andoni river. This creek has four major channels, Dor Nwezor, Koola Tobsoi, Koola Seato and Kpador. The Dor Nwezor and Kpador seaward are the two major channels that distributes saline waters in and out of Bodo Creek, which connects Bodo Creek to Opobo channel (an adjunct links of Andoni and Bonny rivers), and to Bonny River respectively. The creek layout, geomorphology and hydrology has been described extensively by Onwugbuta-Enyi et al., (2008), Zabbey et al., (2010) [8,9] Bodo Creek serves as a major livelihood Support base for the Bodo natives and their neighbours[10] Providing ready fishing incentives, small and medium aquaculture, transportation, cassava fermentation, domestic waste disposal[8] Bodo Creek bio-resources access is open to every person as I lacks any organized structures to check, manage and regulate the creek basin exploitation rates aside the feeble community imposed laws, which are grossly violated due to lack of enforcement and eroding traditional authorities respect[9]

\section{Material and methods}

The extent of dispersion can be measured by the determination of the coefficient of dispersion (D) or by its dimensionless group called the dispersion number $(\delta)$. There are several methods of evaluating dispersion and these methods are grouped into empirical and experimental method.

For the experimental method (tracer studies), the tracer is usually introduced at the influent of the measured reach to be studied, and at the effluent end samples are collected at time intervals or by measuring the tracer concentration using an instrument. The coefficient of dispersion can be derived experimentally using techniques, these techniques could be constant distance variable time method or the variable distance-time method.

The data generated from the tracer experiment can be estimated using empirical or theoretical equations based on the relationship between dispersion and variance by the statistical moment method based on levenspiel and smith (1957) moment approach [11]

$$
\delta=\frac{1}{8}\left[\sqrt{8 \sigma^{2}+1}-1\right]
$$

$\delta=$ Dispersion number, $\sigma^{2}=$ Normalized variance, this is calculated from constant distance variable time tracer experiment and is given by;

$$
\sigma^{2}=\frac{1}{\theta^{2}}\left[\frac{\sum_{i=1}^{n} C_{i} t_{i}^{2}}{\sum_{i=1}^{n} C_{i}}-\theta^{2}\right]
$$

$\mathrm{t}=$ Time after tracer injection (seconds)

$\mathrm{c}=$ Concentration of tracer at the downstream (mg/l), $\theta=$ Average flow time, given by the Marecos do monte and mara (1987)[12]

$$
\theta=\frac{\sum_{i=1}^{n} C_{i} t_{i}}{\sum_{i=1}^{n} C_{i}}
$$

For the variable distance time technique, the following equations have been derived by Agunwamba (1997) [13]

$$
\delta=\frac{1}{29.2}\left[\sqrt{1+15 \sigma^{2}}-1\right]
$$

And 


$$
\sigma^{2}=\frac{\sum_{i=1}^{n}\left\{\frac{\tau}{1-\varepsilon}\right\}^{2} C}{\sum_{i=1}^{n} C}-\left[\frac{\sum_{i=1}^{n}\left\{\frac{\tau}{1-\varepsilon}\right\} C}{\sum_{i=1}^{n} C}\right]^{2}
$$

Where the summation is taken over all the uniformly spaced readings. The parameter $\tau=\frac{t}{\theta}$ and $\varepsilon=\frac{X}{L}$.

$\mathrm{L}$ is the channel length and

$\mathrm{X}$ is the distance from the outlet and $\mathrm{t}$ is the time after tracer injection.

The dimensionless dispersion number is related to the dispersion coefficient by[3]

$$
\delta=\frac{D}{u L}
$$

$D=$ dispersion coefficient, $\mu=$ flow velocity of stream, $L=$ sample length of stream

A governing equation of a parabolic type in one dimension can be used to describe a solute released into a river, based on convection-dispersion process in which the hydraulic regime is characterized as steady uniform or non-uniform flow.

$$
D_{x} \frac{\partial^{2} B}{\partial X^{2}}-V_{x} \frac{\partial B}{\partial X}+S S_{B}=0 .
$$

$\mathrm{B}=$ concentration of tracer used $(\mathrm{mg} / \mathrm{l})$

$\mathrm{D}_{\mathrm{x}}=$ longitudinal dispersion coefficient (sq.km/day), $\mathrm{V}_{\mathrm{x}}=$ average stream flow velocity ( $\mathrm{km} /$ day), $\mathrm{SS}_{\mathrm{B}}=$ source and $/$ or sink for discharge along the river stretch $(\mathrm{mg} / \mathrm{l})$ and, $\mathrm{X}=$ distance along river stretch $(\mathrm{km})$.

For the ease of calculations, it is assumed that the values for D and V estimated from the tracer experiment are constant along the entire river stretch.

The physical parameters relevant to estimating the longitudinal dispersion coefficient of a given water body include velocity, depth of river, river channel width, and flow rate of the water body. The coefficient of dispersion for a given system is not constant but varies as these parameters changes[6] Early methods of measuring dispersion coefficients applied experimental techniques until 1920 when Taylor considered the spread of particles in a moving fluid, describing the longitudinal dispersion concept as a one dimensional process showing the effects of convection and diffusion within the cross-section of a uniform channel. The coefficient of dispersion was expressed as

$$
D=(10.06+0.05) A U^{*}
$$

$\mathrm{A}=$ Hydraulic Diameter $(\mathrm{m})$

$\mathrm{U}^{*}=$ Shear Velocity $(\mathrm{m} / \mathrm{s})$

Subsequently, a laboratory measurement and assumption of velocity profile extended Taylor's method for an open or infinitely large channel[22]

$$
D=5.93 H U^{*}
$$

$\mathrm{H}=$ flow depth $(\mathrm{m})$

Elder's equation was further improved upon by showing it significantly underestimated the coefficient of dispersion, due to neglect of the transverse velocity profile across the river thus leading to the integral equation that takes in to account the lateral velocity profile in place of the vertical velocity profile.

$$
\mathrm{D}=-\frac{1}{\mathrm{~A}} \int_{0}^{\mathrm{B}} \mathrm{h}(\mathrm{y}) \cdot \mathrm{u}^{\prime(y) \int_{0}^{\mathrm{y}} \frac{1}{\varepsilon_{\mathrm{y}} \mathrm{h}} \int_{0}^{\mathrm{y}} \mathrm{h}(\mathrm{y}) \cdot \mathrm{u}^{\prime}(\mathrm{y}) \cdot d y d y d y}
$$


However, the challenge with this equation was in its difficulty in determining the coefficient of dispersion as a result of the lack of consideration given to the transverse depth and velocity profile thus, in 1975 he came up with an equation which included the velocity deviation, triple integral, and transverse coefficient approximations[14]

$$
D=0.011 \frac{U^{2} B^{2}}{H U^{*}}
$$

$\mathrm{U}=$ Average velocity $(\mathrm{m} / \mathrm{s}), \mathrm{B}=$ Channel width $(\mathrm{m})$

Again, an equation for the estimation of the coefficient of dispersion using the one dimension mass transport and a one dimension flow equation for the fond number $(F)$ not greater than 0.5 was proposed by Mcquivey and Keefer, 1974[15]

$$
D=\frac{0.058 Q}{S W}
$$

$\mathrm{Q}=$ Volumetric Flow Rate $\left(\mathrm{m}^{3} / \mathrm{s}\right), \mathrm{S}=$ Energy slope (Dimensionless), W= River Width (m)

While, Liu (1977) proposed an equation using the Fisher's equation and taking the lateral velocity gradient in to consideration as[16]

$$
D=\beta \frac{U^{2} B^{2}}{H U^{*}}
$$

In which $\beta$ represents a function of the channel's shape and its velocity distribution profile, expressed as

$$
\beta=0.18\left(\frac{U^{*}}{U}\right)^{1.5}
$$

Iwasa and Aya (1991) further improved the equation using laboratory and previous field data's for the prediction of the coefficient of dispersion in a natural stream [17]

$$
\frac{D}{H U^{*}}=2.0\left(\frac{B}{H}\right)^{1.5}
$$

Seo and Cheong (1998) developed an equation using regression analysis for one step Huber method and dimensional analysis as[18]

$$
\frac{D}{H U^{*}}=5.915\left(\frac{B}{H}\right)^{0.620}\left(\frac{U}{U^{*}}\right)^{1.428}
$$

Deng et al (2001) also derived an equation with the coefficient of transverse mixing and this proved that an equation using the transverse mixing coefficient could determine the longitudinal dispersion coefficient accurately in rivers [19]

$$
\frac{D}{H U^{*}}=\frac{0.15}{8 \varepsilon_{r 0}}\left(\frac{B}{H}\right)^{5 / 3}\left(\frac{U}{U^{*}}\right)^{2}
$$

$\varepsilon_{r 0}$ is the transverse mixing coefficient, calculated using the formula

$$
\varepsilon_{r 0}=0.145+\left[\frac{1}{3520}\right]\left[\frac{U}{U^{*}}\right]\left[\frac{B}{H}\right]^{1.38}
$$

Kashefipour and Falcorner (2002) proposed their equation for dispersion coefficient using the data collected and obtained from rivers in United states of America[20] The equation is expressed as;

$$
D=10.612 H U\left[\frac{U}{U^{*}}\right]
$$

This equation was integrated into that by Seo and Cheong (1998) to produce an equation as follows; 


$$
D=\left[7.428+1.775\left[\frac{B}{H}\right]^{0.620}\left[\frac{U^{*}}{U}\right]^{0.572}\right] H U\left[\frac{U}{U^{*}}\right]
$$

Sahay and Dutta [21]

$$
\frac{D}{H U^{*}}=2\left[\frac{B}{H}\right]^{0.96}\left[\frac{U}{U^{*}}\right]^{1.25}
$$

\subsection{Criteria for Comparison of Empirical Models}

The determination of the coefficient of longitudinal dispersion is of utmost importance, as unreliable estimation would result in mistakes, and errors in the management of the river. Thus the use of statistical techniques using the observed field data is important in defining the dispersion coefficient and for comparing the accuracy of results from other empirical models.

These statistical models are as follows [22]

Discrepancy ratio $(\lambda)$

$$
\lambda=\log \frac{D_{P}}{D_{M}}=\log \left(D_{P}-D_{M}\right)
$$

Root mean square (RMS)

$$
R M S=\frac{1}{N} \sqrt{\sum_{i=1}^{N}\left(D_{P}-D_{M}\right)_{i}^{2}}
$$

Mean Absolute Error (MAE)

$$
M A E=\frac{1}{N} \sum\left|\left(D_{P}-D_{M}\right)_{i}\right|
$$

DP is the calculated coefficient of dispersion

DM is the measured field value of the coefficient of dispersion, $\mathrm{N}$ is the number of data

The discrepancy ratio is dependent on the following conditions

If $\lambda=0$ this shows equality of calculated value with measured value.

If $\lambda>0$ this shows that the model overestimates the coefficient of dispersion.

If $\lambda<0$ this shows that the coefficient of dispersion is underestimated.

Each model's accuracy is categorized by the number $\lambda$ value between \pm 0.3

\section{Results and discussion}

The results obtained from the experimental study and data gathering are shown thus.

The absorbance of the standard solutions prepared using a spectrophotometer is shown in Table 1 with its corresponding plot of absorbance against concentration in Figure 1. A straight line graph is deduced from the plot, which is referred to as calibration curve. Also, more values of absorbance with its concentration value can be determined from the calibration curve. 
Table 1 Absorbance of the standard solution

\begin{tabular}{|l|l|}
\hline Absorbance & Concentration $\mathbf{( g / L )}$ \\
\hline 12 & 20 \\
\hline 22 & 40 \\
\hline 30 & 60 \\
\hline 39 & 80 \\
\hline 48 & 100 \\
\hline 56 & 120 \\
\hline
\end{tabular}

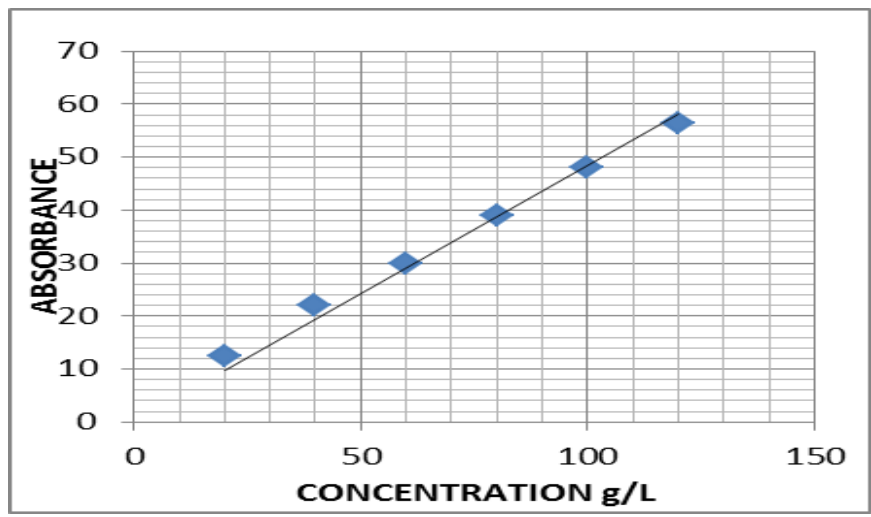

Figure 1 Absorbance against Concentration

The absorbance of the standard solutions prepared using a spectrophotometer is shown in Table 1 with its corresponding plot of absorbance against concentration in Figure 1. A straight line graph is deduced from the plot, which is referred to as calibration curve. Also, more values of absorbance with its concentration value can be determined from the calibration curve.

Table 2 Sample Concentration with Time

\begin{tabular}{|l|l|}
\hline $\begin{array}{l}\text { Concentration } \\
\text { (g/L) }\end{array}$ & Time (Sec) \\
\hline 0 & 0 \\
\hline 11.5 & 3 \\
\hline 22 & 8 \\
\hline 36 & 10 \\
\hline 24 & 15 \\
\hline 15.4 & 17 \\
\hline 7 & 20 \\
\hline 2 & 23 \\
\hline 0 & 30 \\
\hline
\end{tabular}




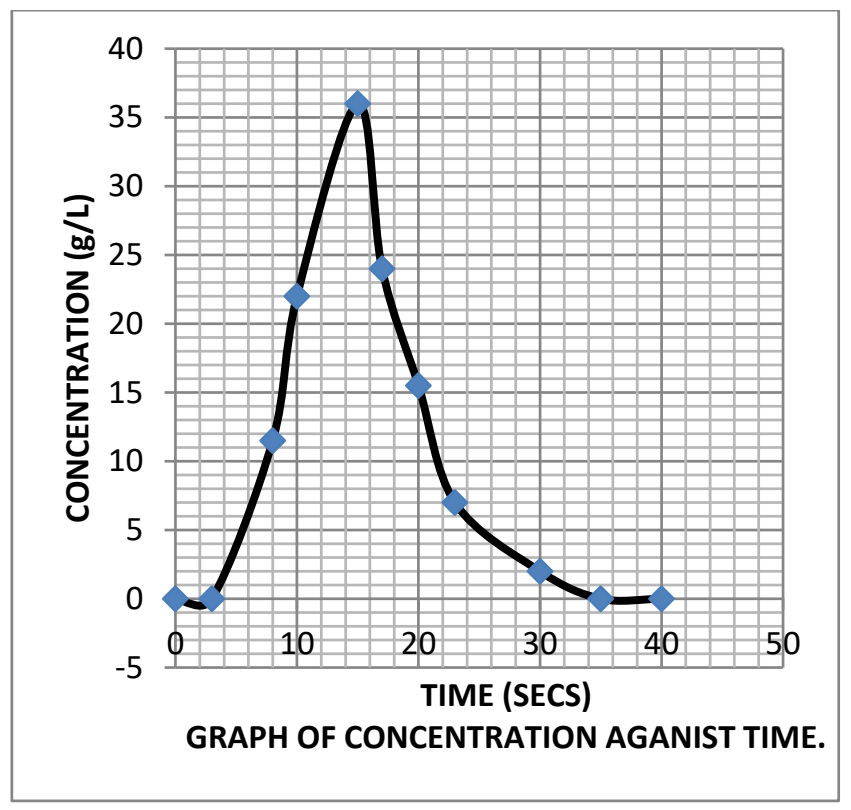

Figure 2 Concentration against Time

The concentration of the samples extrapolated from the calibration curve at time interval of sampling is shown in Table 2 , while the plot of the sample concentration against the travel time is shown in Figure 2. This plot yielded a dumb bell shaped polynomial function, which shows that as the tracer travels from its point of introduction upstream, its concentration increases as time increases until it gets to the peak travel concentration, and starts declining as the time increases downstream in the direction of flow of the river.

Table 3 Comparison of the measured and tmodels predicted values of coefficient of dispersion Evaluated Dispersion Coefficient $=0.5702 \mathrm{~m}^{2} / \mathrm{s}$

\begin{tabular}{|l|l|l|l|l|}
\hline Models & $\begin{array}{l}\text { Dispersion } \\
\text { Coefficient } \\
\left(\mathbf{m}^{2} / \mathbf{s}\right)\end{array}$ & $\begin{array}{l}\text { Discrepancy } \\
\text { Ratio }\end{array}$ & $\begin{array}{l}\text { Mean Absolute } \\
\text { Error }\end{array}$ & $\begin{array}{l}\text { Root Mean } \\
\text { Square }\end{array}$ \\
\hline Taylor & 2.4593 & 0.2764 & 0.4126 & 0.2658 \\
\hline Elder & 1.4620 & -0.0497 & 0.2081 & 0.1496 \\
\hline Fisher & 0.1948 & 0.0417 & 0.0548 & -0.0596 \\
\hline Mcquivey \& Keefer & 25.3417 & 1.3940 & 2.7524 & 2.8150 \\
\hline Liu & 2.4632 & 0.2772 & 0.2103 & 0.2663 \\
\hline Iwasa \& Aya & 9.4129 & 0.9331 & 0.9525 & 1.0440 \\
\hline Seo \& Cheong & 6.3053 & 0.7586 & 0.6374 & 0.6978 \\
\hline Deng et al & 1.1586 & -0.2303 & 0.0617 & 0.1221 \\
\hline Kashefipour \& Falconer 1 & 3.6887 & 0.4939 & 0.3465 & 0.4049 \\
\hline Kashefipour \& Falconer 2 & 4.4744 & 0.5915 & 0.4338 & 0.4931 \\
\hline Sahay \& Dutta & 4.0353 & 0.5397 & 0.3850 & 0.4439 \\
\hline
\end{tabular}

The results of the statistical methods used for the comparison of the theoretical models from literature for the predicted coefficient of dispersion and the measured value are shown in Table 3. It can be determined from the table that deduced models of Elder, Deng et al, Taylor and Liu gave discrepancy ratios values of $-0.0497,-0.2303,0.2764$ and 0.2772 respectively, which fell within the accuracy range of -0.3 to 0.3 . Thus, these models closely predicted the measured value 
of coefficient of dispersion. The other models overestimated the coefficient of dispersion as their values are above 0.3 , hence these models result fall outside the accuracy limit of method. Deng et al and Fisher yielded the least mean absolute error values of 0.0617 and 0.0417 closest to zero, thus indicating high degree of accuracy of their models as compared to the other models considered. Deng et al also showed the least root mean square value of 0.1221 as compared to all the other models considered in this study. The model of Deng et al had the closest result as the measured value after the comparison using all three statistical methods.

\section{Conclusion}

The comparison of the experimental and theoretical results using statistical methods shows that the equation of fisher, Mcquivey and keefer, Iwasa and Aya, Seo and Cheong, Kashefipour and Falconer and Sahay and Dutta over-estimated the analysis and results exceeds the limit of accuracy of the discrepancy ratio, while Taylor, Elder, Liu and Deng et al under estimated the measured dispersion coefficient but results are within the accuracy range. Also, the equations of Elder, Fisher and Deng et al gave the closest values to zero, hence they predicted the measured dispersion coefficient closely using the mean absolute error measure. Similarly the equation Deng et al yielded the least root mean square error value closest to zero, indicating that this equation closely predicted the measured dispersion coefficient. Thus, the equation of Deng et al was considered the most reliable method of predicting the longitudinal coefficient of dispersion of Dor Nwezor section of the Bodo-Bonny River, having closely fulfilled the conditions of the statistical methods applied as compared to the other models. The predicted value by this method showed the least root mean square value of 0.1221 , and a mean absolute value of 0.0617 close to zero with discrepancy ratio of -0.2303 , which falls within the accepted accuracy range of -0.3 to 0.3 . The accuracy of this model can be attributed to the inclusion of the coefficient of transverse dispersion in its model.

\section{Compliance with ethical standards}

\section{Acknowledgments}

The authors wish to express their profound gratitude to the staffs (academics and non-academics) of the Department of Environmental Engineering and Technology, University of Port Harcourt for their support and assistance in carrying out this research study. More power to your elbows.

\section{Disclosure of conflict of interest}

We (Nwidadah Baridakara and Adeloye Olalekan Michael) the authors of the article "Curve Fitting the Hydrodynamic and Dispersion Characteristics of Pollutant Released in an Inland Water System" wish to state that there are no conflicts of interest in this our research article.

\section{References}

[1] Jobson, H. E. USGS Water-Resources Investigation, Report No 2014; 96-4013

[2] Metcalf \& Eddie Waste Water Engineering: Treatment and Reuse.Boston: McGraw-Hill publishers, 2003; $230-231$

[3] Agunwamba, J. C. Waste Engineering and Management Tool. Enugu, Nigeria: Immaculate Publications Limited, $2001 ; 205-246$

[4] American Heritage Dictionary of English Language. Houghton: Mifflin Harcourt Publishing Company 2016

[5] Eckert, M The dawn of fluid dynamics-A discipline between science and technology. Wiley publisher 2006.

[6] Naved, A. Estimating the Coefficient of Dispersion for a Natural Stream. World Academy of Science and Technology, $2008 ; 44: 345-347$

[7] UNEP 2011. Environmental Assessment of Ogoni Land. United Nations Environmental Programme

[8] Onwugbuta-enyi J., Zabbey, N. \& Erondu, E. S. Water Quality of Bodo Creek in the Lower Niger Delta Basin. Advances in Environmental Biology, 2008; 2 (3):132-136.

[9] Zabbey, N., Hart, A. I., \& Wolff, W. J. Population Structure, Biomass and Production of West Africa Lucinid Kelestistes Rhizoecus (Bivalvia Mollusca) in Sivibilagbara Swamp at Bodo Creek, Niger Delta, Nigeria. International Journal of Aquatic Science. 2010; 651 (1):193-203 
[10] Powell, C. B, Hart, A. I. \& Deekae, S. Market Survey of the Periwinkle Tympanotomus Fuscatus in Rivers State: Size, Price, and Exploitation Level. proc. of fisheries society of Nigeria (FISCON), Port Harcourt, 1985; 55-61

[11] Levenspiel, O. \& Smith W. K. Notes on Diffusion Type Model for Longitudinal Mixing of Fluids in Flow. Chem. Engng. Sci., 1957; 16:219-233

[12] Marecos do monte, M. F. H. \& Mara, D. D. The Hydraulic Performance of WSP in Portugal. Wat. Sci. Techn., 1987; 19 (12): 219-227

[13] Agunwamba, J. C. Reduction of Sampling Time in Tracer Studies Water Environment Res., 1997; 69 (3):343-349

[14] Fisher, B. H. Discussion on Simple Method for Predicting Dispersion in Streams by Mcquivey and Keefer Journal of the Environmental Engineering Division, 1975: 101 (3):453-5

[15] Mcquivey, R. S. \& Keefer, T. N. Simple Method for Predicting Dispersion in Streams. Journal of the Environmental Engineering Division, 1974; 100 (4):997-1011

[16] Liu, H. Predicting Dispersion Coefficient of Stream. Journal Environ. Eng., 1977; 103 (1):59-69

[17] Iwasa, Y. \& Aya, S. Predicting Longitudinal Dispersion Coefficient in Open-Channel Flow. Proceeding of International Symposium in Environmental Hydraulic, Hong Kong, 1991; 505 -510

[18] Seo, W. \& Cheong, T. S, Prediction of Longitudinal Dispersion Coefficient in Natural Streams. Journal of Hydraulic Engineering, 1998; 124 (1):25-32.

[19] Deng, Z. Q., Singh, V. P. \& Bengtsson, L. Longitudinal Dispersion in Straight Rivers. Journal of Hydraulic Engineering, 2001; 127 (11):919-927

[20] Kashefipour, S. M. \& Falconer, R. A. Modeling Longitudinal Dispersion Coefficient in Natural Channel Flow using ANN's. .International Conference on Fluvial Hydraulics, Belgium, River Flow, 2002b; 111-116.

[21] Sahay, R.R \& Dutta, S. S. Prediction of Dispersion Coefficient in Natural Rivers using Genetic Algorithm. Hydrology Research 2009; 40:544-552

[22] Ayyoubzadeh, S. A, Faramarz, M. \& Mohammadi, K. Estimating Longitudinal Dispersion Coefficient in Rivers. Asian pacific association of hydrology and water resources conference, 2004; 1-7

[23] Elder, J. W. The Dispersion of Marked Fluid in Turbulent Shear Flow. Journal of the Sanitary Engineering Division, 1959; 5 (1):544-60

[24] Taylor, G. I. (1954). Dispersion of Matter in Turbulent Flow Through a Pipe. Proceedings of the Royal Society A Mathematical, Physical and Engineering Science, 1954; 223:446-468 